\title{
Cambio institucional, discurso y política. Una propuesta de análisis desde el postestructuralismo
}

\author{
JuAN MANUEL REYNARES*
}

Artículo recibido: 15 de julio de 2015

Artículo aprobado: 13 de diciembre de 2016

Doi: http://dx.doi.org/10.12804/revistas.urosario.edu.co/desafios/a.4022

Para citar este artículo: Reynares, J. M. (2017). Cambio institucional, discurso y política. Una propuesta de análisis desde el postestructuralismo. Desafíos, 29(2), 199-236. doi: http:// dx.doi.org/10.12804/revistas.urosario.edu.co/desafios/a.4022

\section{Resumen}

Este articulo contribuye a la discusión sobre el vinculo entre instituciones y discurso en la ciencia política. Para ello, recupera algunos aportes del institucionalismo discursivo que han subrayado cómo la dimensión simbólica de la política permite comprender los cambios institucionales de un modo del que adolece la mayoría de las perspectivas canónicas del lenguaje institucionalista. No obstante dicha contribución, el presente trabajo pretende mostrar cómo sus presupuestos ontológicos y epistemológicos limitan la noción de politica a la consecución del consenso y a la provisión de razones por parte de actores provistos de una racionalidad comunicativa, lo que relega su carácter contingente y disputado. Frente a ello, presenta una perspectiva onto-epistemológica postestructuralista que subraya el carácter constitutivamente descentrado y conflictivo de la objetividad social en el marco de la disputa entre proyectos hegemónicos antagónicos. A partir de esta propuesta se enfatiza en los tropos retóricos de la metáfora

\footnotetext{
* Doctor en Ciencia Política por el Centro de Estudios Avanzados de la Universidad Nacional de Córdoba. Becario Posdoctoral CONICET. Docente en la Universidad Nacional de Villa María. Correo electrónico: juanmreynares@gmail.com. ORCID: orcid. org/0000-0001-5483-0614
} 
y la metonimia como recursos discursivos que permiten comprender la dinámica de desplazamiento y de condensación significante mediante la cual se producen los cambios institucionales. En la última parte del texto, se ponen en juego algunos de estos conceptos en el análisis de la Reforma del Estado implementada en la provincia argentina de Córdoba entre 1999 y 2000.

Palabras clave: cambio institucional, discurso; retórica, postestructuralismo, reforma estatal

\title{
Institutional Change, Discourse and Politics. A Poststructuralist Research Proposal
}

\begin{abstract}
The article deals with the discussion about the relation between institutions and discourse in political science. To do so, it recovers some contributions from discursive institutionalism that have outlined the way in which the symbolic dimension of politics allows for the comprehension of institutional change - something underestimated by most mainstream perspectives in institutionalism. The article shows how the ontological and epistemological assumptions of mainstream institutionalism limit the notion of politics to the achievement of consensus and providing reasons by communicative rationality of given actors, which, in turn, diminishes the contingent and contested character of politics. As a result, the article puts forward a poststructuralist perspective which underlines the constitutively decentered and conflictive character of social objectivity in the struggle among antagonistic hegemonic projects. Rhetorical tropes such as metaphor and metonymy are emphasized as resources in order to understand the dynamics of meaning displacement and re-totalization through which institutional change is produced. The article concludes with how some of these concepts can be used in the analysis of state reform in the province of Córdoba, Argentina, between 1999 and 2000.
\end{abstract}

Keywords: Institutional change, discourse; rhetoric, poststructuralism, state reform 


\title{
Mudança institucional, discurso e política. Uma proposta de análise desde o pós- estruturalismo
}

\begin{abstract}
Resumo
Este artigo contribui à discussão sobre o vinculo entre instituições e discurso na Ciência Política; Para isso, recupera alguns aportes do Institucionalismo Discursivo que têm sublinhado como a dimensão simbólica da política permite compreender as mudanças institucionais, de um modo do que adoece a maioria das perspectivas canónicas da linguagem institucionalista. Não obstante dita contribuição, o presente trabalho pretende mostrar como os seus pressupostos ontológicos e epistemológicos limitam a noção de política à consecução do consenso e a provisão de raz̃ões por parte de atores providos de uma racionalidade comunicativa, o que relega o seu carácter contingente e disputado. Frente a isto, apresenta uma perspectiva onto-epistemológica pós-estruturalista, que sublinha o carácter constitutivamente descentrado e conflitivo da objetividade social, no marco da disputa entre projetos hegemônicos antagônicos. A partir desta proposta se enfatiza nos tropos retóricos da metáfora e a metonímia como recursos discursivos eu permitem compreender a dinâmica de deslocamento e condensação significante mediante a qual se produrem as mudanças institucionais. $\mathrm{Na}$ última parte do texto, põem-se em jogo alguns destes conceitos na análise da Reforma do Estado implementada na provincia argentina de Córdoba entre 1999 e 2000. Palavras-chave: mudança institucional, discurso, retórica, pós-estruturalismo reforma estatal
\end{abstract}

\section{Introducción}

El siguiente artículo pretende ubicarse en el contexto del reciente debate teórico y analítico dentro de la ciencia política sobre la relación entre instituciones y discurso. Por una parte, dentro de las numerosas perspectivas analíticas institucionalistas, ha habido un creciente interés por las ideas y el discurso - tanto en su contenido sustantivo como en el proceso interactivo de su configuración (Schmidt, 2010)_para dar cuenta de la dimensión del cambio institucional que suele ser relegada o de difícil explicación en las perspectivas canónicas. Sin embargo, la delimitación de lo discursivo al aparato categorial 
de la lógica comunicativa basada en la obra de Habermas, dentro de una caracterización deliberativa y consensual de la política (Schmidt, 2008; Pedersen, 2008), deja de lado los componentes conflictivos y contingentes en esta última. Por otra parte, los aportes de la Teoría Política del Discurso (TPD), en las diversas variantes de análisis que posibilitó la obra de E. Laclau y C. Mouffe, han dado lugar a las instituciones bajo diversas denominaciones (Panizza y Miorelli, 2013), pero no ha habido una preocupación sistemática por la dimensión institucional de la política, e incluso algunas lecturas sobre la TPD han subrayado una aparente distancia entre discurso e instituciones.

En torno a este debate en ciernes, en este artículo planteamos que el desarrollo teórico de E. Laclau (2014) abre una superficie de inscripción para el desarrollo de un lenguaje analítico que se haga cargo de los presupuestos ontoepistémicos de la Teoría Política del Discurso sin que ello implique desmerecer el rol de las instituciones en la política. En particular, sostendremos que es posible explicar el cambio institucional mediante desplazamientos metonímicos y retotalizaciones metafóricas que poseen implicancias en la delimitación del ámbito y función de las instituciones.

Para desarrollar esta hipótesis, nuestro argumento tendrá tres partes. En la primera, presentaremos algunos de los avances más significativos en la inclusión de elementos simbólicos dentro del lenguaje institucionalista. Partiendo de las limitaciones y posibilidades que encontramos en ellos, en un segundo momento plantearemos los efectos analíticos de una reubicación ontoepistémica postestructuralista, en la que lo social se estructura y adquiere significación discursivamente - lo que subraya su carácter intrínsecamente incompleto- a través del antagonismo social y la dislocación. Desde allí, desarrollaremos las nociones retóricas de metonimia y metáfora en el marco más general de la teoría de la hegemonía. Finalmente, pondremos en juego este andamiaje conceptual en el análisis de un proceso de cambio institucional como lo fue la reforma estatal de la Provincia de Córdoba en el año 2000 al mostrar cómo los promotores de la reforma abrevaron en un escenario hegemónico estructurado alrededor de una lógica empresarial. 


\section{Institucionalismo discursivo y lógica comunicativa}

Dentro de la ciencia política contemporánea, los estudios "neoinstitucionalistas" han ocupado un lugar central. Existen numerosas taxonomías sobre las vertientes al interior de este lenguaje a fines del siglo XX, según cómo se caracterice a las instituciones, cómo se analice el vínculo entre instituciones y agencia, y el lugar destinado a la comprensión del cambio institucional (Hall y Taylor, 1996). Siguiendo a Campbell y Pedersen (2001), es posible distinguir allí el institucionalismo de la elección racional, el organizacional y el histórico. Desde los enfoques de elección racional, se plantea que los individuos utilizan a las instituciones como medios para alcanzar la mejor relación costo-beneficio en un cálculo estratégico en que la estructuración normalizada de las interacciones — reduciendo los cursos de acción posibles, proveyendo información o coacción— facilita la actividad del individuo, pero este determina sus intereses y rango de preferencias fuera, y antes, de la interacción institucional (Rothstein, 1996, p. 218). La perdurabilidad de las instituciones se sostiene hasta el grado en que no son interrumpidas por eventos exógenos como una guerra, o mientras los cambios en oportunidades alternativas no lleven a actores individuales y coaliciones a defeccionar de ciertos arreglos institucionales por otros. De esta manera, el cambio en las instituciones necesita en este esquema de un recurso externo que sea capaz de explicarlo.

El segundo, denominado neoinstitucionalismo organizacional, abreva en los estudios existentes sobre la dinámica de las organizaciones sociales, provenientes de la sociología. Las instituciones son consideradas capaces de proveer paradigmas positivos sobre cómo hacer algo, en la forma de esquemas o guías sustantivas para la acción práctica, por lo que su perdurabilidad estará marcada por la socialización, interacción, o legitimación de manera tal que cualquier idea alternativa sea planteada como imposible (Clemens y Cook, 1999, pp. 445-446).

El neoinstitucionalismo histórico, en cambio, enfatiza en cómo las instituciones formales en contextos nacionales concretos, y situados en escenarios de larga duración, determinan distintos resultados en 
la manera en que los actores son capaces de actuar, negociar y llegar a acuerdos. En esta línea, los cambios suelen plantearse a partir de transformaciones en los conflictos de intereses, provocando trayectorias de modificaciones progresivas, básicamente de aprendizaje, de retroalimentación y de experimentación.

De este modo, las tres corrientes institucionalistas admiten la posibilidad de cambio de las instituciones bajo la figura de modificaciones en el contexto que influyen entonces en la estructura interna de la institución. No obstante, no ofrecen herramientas analíticas para comprender las dinámicas propias de la transformación en la institución. En este sentido, en una revisión de la bibliografía institucionalista se plantea que "es un hecho admitido que este [el cambio institucional] es uno de los aspectos más difíciles para el análisis institucional y, por lo tanto, su mayor debilidad" (Rothstein, 1996, p. 227). Al plantear que la institución y el contexto son esencialmente diferentes, el cambio en las instituciones pasa a ser considerado del orden de lo accidental que viene a adecuarse a lo ya ocurrido fuera de su ámbito de influencia. En tanto las instituciones son vistas como reglas de juego en una instancia separada del uso que los individuos hacen de ella, la presencia plena de la institución se ve modificada accidentalmente por aquellas sucesivas puestas en práctica de sus principios. En este esquema, entonces, la transformación se explica por otras instancias de lo social, dejando a la institución tan solo la posibilidad de adecuarse a las nuevas circunstancias o decaer.

Frente a estas dificultades compartidas en mayor o menor medida por el lenguaje analítico neoinstitucional sobre el vínculo entre contexto, agencia individual e institución y sobre la comprensión de los procesos de cambio, se han registrado tempranos intentos de incorporar la dimensión simbólica al estudio histórico u organizacional ${ }^{1}$. En épocas más recientes, han emergido intervenciones analíticas que llaman a una revisión profunda de las presunciones teóricas y metodológicas del institucionalismo para poder responder de manera sistemática y

1 Puede remitirse a March y Olsen (1989) o Hall (1989) como pioneros en esta tendencia. 
comprehensiva al problema del cambio institucional, profundizando sobre el modo en que instituciones y contextos históricos se interrelacionan. Pedersen (2008), por caso, hace una serie de preguntas respecto de la teoría institucional en la ciencia política sobre cuestiones ontológicas, epistemológicas y metodológicas que abarcan desde la definición misma de institución y su diferencia respecto de la organización formal, hasta la dimensión normativa de estos estudios, pasando por el rol del lenguaje, la relación con el individuo, la racionalidad presupuesta y los procesos de cambio.

Por otra parte, en los últimos años, Schmidt $(2008,2010)$ ha postulado un nuevo Institucionalismo Discursivo (ID) en el que incluye de manera genérica aquellos trabajos que, al participar de algunas de las perspectivas más canónicas dentro del neoinstitucionalismo, han dado preeminencia a las ideas o al discurso para explicar procesos de transformación institucional con especificidades nacionales vinculados a la emergencia del neoliberalismo de los últimos cuarenta años ${ }^{2}$. El ID reúne los trabajos que consideran los marcos ideacionales o las trayectorias discursivas en cada caso como variables explicativas para entender las particularidades con que esas transformaciones fueron llevadas adelante (Schmidt, 2010). De modo específico, además, el ID que propone Schmidt incorpora una propuesta de análisis que desplaza la exterioridad entre agente e institución para enfatizar el vínculo recíproco entre uno y otra. En su propuesta, el discurso se refiere al proceso interactivo por el que se coordinan actores políticos en la elaboración de proyectos institucionales a través de reconfiguraciones de memorias y narrativas colectivas.

\footnotetext{
2 En general, esta literatura especializada se interroga por los cambios que los últimos desarrollos del capitalismo han tenido en diversos países centrales (Estados Unidos, Inglaterra, Alemania, Francia, Italia, países escandinavos, España, Japón, entre otros). En pocas palabras, las experiencias nacionales del neoliberalismo se explican, en general, en clave comparada debido a características institucionales - ya sea de su sistema productivo, de su organización estatal, administrativa y gubernamental, de la presencia de corporaciones, o de la dinámica de su sistema de partidos - en cada país analizado. Téngase en cuenta, para una mirada sinóptica dentro de la numerosa literatura, a Campbell y Pedersen (2001).
} 
Tanto Pedersen como Schmidt pretenden distinguirse de las perspectivas institucionalistas más canónicas. En primer lugar, ambos subrayan la ligazón entre una subestimación de la dimensión discursiva en el lenguaje neoinstitucionalista y el obstáculo que este presenta para el desarrollo de una "teoría del cambio institucional". Discurso y cambio surgen entonces como dos caras de un mismo problema: lo que no puede contemplarse —esto es, el carácter dinámico, cambiante y contingente de la realidad social — se deriva de un aspecto discursivo no relevado lo suficiente $-\mathrm{o}$ mejor, mirado de una manera que lo vuelve accesorio y secundario- en la literatura neoinstitucionalista canónica. Allí adquiere relevancia el énfasis de ambos autores en suprimir la distancia entre agente e institución, para dar cuenta en cambio de su correlación. En el caso de Pedersen, el redireccionamiento de su análisis hacia una pregunta por el sentido de los fenómenos, y ya no por la conducta de los actores - interrogante este último que, alega, ha caracterizado al neoinstitucionalismo tradicional—, implica cuestionarse a su vez acerca de hasta qué punto es posible distinguir entre realidades institucionales exógenas e interpretaciones endógenas (Pedersen, 2008, p. 10).

Similar dirección corren los planteamientos del ID de Schmidt, quien remarca que el discurso es el proceso interactivo de coordinación y comunicación a lo largo de la implementación de políticas públicas entre diversos actores, quienes ponen en juego diversas habilidades para reconocer el carácter apropiado de una conducta o decisión, pero también para cuestionar la validez de los arreglos institucionales vigentes. $\mathrm{Al}$ recalcar que el discurso es entonces eminentemente dinámico, la autora también rechaza una estanca separación entre las instituciones y las interpretaciones que los actores realizan de ellas. Schmidt plantea que las instituciones son "internas a los agentes perceptivos, sirviendo tanto como estructuras (de pensamiento, habla y acción) que constriñen a los actores como constructos (de pensamiento, habla y acción) creados y cambiados por esos actores" (Schmidt, 2008, p. 6).

Esta doble caracterización de la institución se relaciona con dos conjuntos de habilidades de los actores, en palabras de Schmidt. 
Las habilidades ideacionales de fondo [background ideational abilities] "apuntalan la habilidad de los agentes para dar sentido a un contexto de significado dado, esto es, de hacerlo bien en términos de las reglas ideacionales o de la 'racionalidad' de un marco institucional discursivo dado" (Schmidt, 2008, p. 6). Por su parte, las habilidades discursivas de primer plano [foreground discursive abilities] apuntan a la lógica de comunicación, "que es un término genérico para lo que Habermas llama acción comunicativa” (Schmidt, 2010, p. 15), mediante la cual se expresan las ideas ya que cualquier actuación al interior de una institución suele ir acompañada de una verbalización de las razones que la regulan. De ese modo, "el discurso, resumidamente, trabaja a dos niveles, en el de todos los días que genera y comunica sobre las instituciones, y en un meta nivel, como un tipo de comunicación crítica de segundo orden entre los agentes sobre lo que sucede en las instituciones" (Schmidt, 2008, p. 6. Énfasis agregado). ${ }^{3}$

Este enfoque neoinstitucionalista discursivo permite, además, integrar a múltiples actores en el análisis del proceso de transformación institucional más allá de los representantes legislativos o los dirigentes de Gobierno. En la dimensión coordinativa del discurso, ciertos colectivos como las coaliciones de apoyo (advocacy coalitions, Sabatier and JenkinsSmith, 1993) o las comunidades epistémicas (epistemic communities, Haas, 1992) construyen la legitimidad de las propuestas de transformación a partir de la exposición de críticas a los resultados alcanzados con las formas institucionales existentes sirviendo de "catalizadores para el cambio al articular las ideas de comunidades discursivas" (Schmidt, 2010 , p. 3). Ellos proveen razones para fundamentar los proyectos de transformación, por lo que se vuelve un componente central del estudio de los cambios institucionales el análisis de la emergencia, caracterización, entorno social y vinculación con las áreas decisoras de estos actores involucrados en la construcción de ideas sobre políticas públicas.

\footnotetext{
3 Esta caracterización de los actores a la base del cambio institucional sustenta una caracterización de estos como agentes perceptivos [sentient, en inglés] que “... no solo pueden pensar, decir y actuar sino también discurrir sobre sus pensamientos, reflexionar sobre sus acciones, declarar sus intenciones, alterar sus acciones como resultados de su razonamiento sobre sus acciones, y decir lo que piensan hacer y cambiar su opinión en respuesta a la persuasión de otros...” (Schmidt, 2010, p. 17).
} 
De este modo, reconocer que las interpretaciones endógenas de los diversos agentes involucrados constituyen a la institución implica asumir al cambio institucional en vínculo con lo que piensan y expresan estos respecto de esas mismas instituciones. La atención se traslada entonces, ya no al sujeto como individuo provisto de una lógica instrumental, sino a los entramados simbólicos en que se sitúan aquellos actores cuya provisión de razones incide en el cambio de las instituciones. Para Pedersen, esto implica hacerse una nueva pregunta en torno a la racionalidad de los actores intervinientes. Una vez rechazada la presencia de un criterio racional por fuera de la propia institucionalidad, es necesario detenerse en los modos en que una conducta se define como apropiada o no en función de cada contexto regulativo. Aquí Pedersen plantea que

la pregunta principal será... cómo los discursos y las instituciones son contextos para lo que es una conducta apropiada y no apropiada. Así, hasta donde lo entiendo, es cómo Habermas entiende también el problema, cuando distingue entre racionalidad comunicativa, estratégica e instrumental, y plantea que todas están relacionadas a reclamos de validez a ser satisfechos solo mediante la comunicación (Pedersen, 2008, p. 27).

$\mathrm{Al}$ reconocer Pedersen la primacía del entorno institucional-discursivo en la configuración de un criterio de racionalidad, identifica esa dimensión discursiva a una posibilidad de acuerdo mediante la comunicación como ha sido planteado por Habermas (1998). Lo discursivo pasa a ser así un registro dado de significados a ser utilizados por individuos bajo los parámetros de una racionalidad comunicativa en búsqueda de un consenso.

De modo similar, para el ID la definición de lo discursivo está íntimamente vinculada con una caracterización de la política que resalta sus elementos deliberativos, subrayando la influencia del planteamiento habermasiano respecto de la racionalidad comunicativa. En este caso, lo discursivo posee dos dimensiones: por un lado, un conjunto de reglas simbólicas "de fondo" que señalan el curso de acción apropiado, y por el otro, una capacidad crítica "de primer plano" que 
implica una racionalidad comunicativa y que da como resultado una argumentación en torno a ciertos reclamos de validez. No obstante, esta caracterización de lo discursivo en las habilidades discursivas de primer plano que se reduce a la provisión de razones no se interroga por aquello que permitiría poner en discusión los modos de hacer uso de la institución y que abriría la posibilidad de dar un sentido novedoso a sus marcos restrictivos.

En otros términos, que los agentes perceptivos sean capaces de debatir sobre la conveniencia de cierto marco institucional no permite comprender su cambio. En este punto, Pedersen viene a completar la crítica al plantear una pregunta más al lenguaje del ID en su pretensión de encarar sistemáticamente el problema del cambio institucional. Si, como parece plantear Schmidt, se da por sentado que los actores con sus capacidades creativas, críticas y comunicativas pueden transformar las instituciones que les son internas, Pedersen se pregunta "¿cómo podemos identificar las condiciones institucionales para que los actores sean provistos con la voluntad y la posibilidad de cambiar la variedad de valores y normas heredados?" (2008, p. 32. Énfasis agregado).

De este modo, no basta con reconocer el carácter constitutivo de las interpretaciones en las conductas de los actores, o con subrayar la capacidad crítica de los individuos para explicar cierto cambio institucional. Además, debemos tomar en consideración los sentidos implicados y disputados para que una situación merezca ser transformada en tanto comienza a formar parte de cierto orden social percibido como injusto, inequitativo o, más en general, ilegítimo. Así, el cambio es cuestión de una voluntad política que no se deriva de alguna racionalidad a priori, tanto comunicativa como instrumental, sino de cierta interpretación social, por lo que está parcialmente determinada por el entramado significativo en que se inserta y que lo persuade más allá de la mera provisión de razones. La pregunta pasa a ser cuáles son las 
condiciones de posibilidad para que en cierto momento se comience a dar razones para modificar una institución ${ }^{4}$.

En torno a una posible respuesta, se vuelve necesario destacar que ese entramado simbólico al interior del cual los involucrados comienzan a justificar una transformación no constituye una situación de habla neutral. Por el contrario, dicho plexo está constituido por diversas posiciones en disputa que configuran entonces un campo discursivo conflictivo y que disponen de mayor o menor capacidad para interpelar al resto, imputando sentidos específicos a ciertos valores o demandas ${ }^{5}$.

El cambio, si es posible por acción de algunos individuos y grupos, no proviene de la mera acción de cualquiera de ellos por su sola capacidad racional comunicativa - lo que volvería a introducir un criterio exógeno de delimitación- sino más bien de una acción parcialmente determinada por una redescripción disputada de lo legítimo. Desde un enfoque postestructuralista, el cambio no se reduce al resultado de la mejor argumentación donde quedan sin problematizar los motivos para que se desencadene un proceso de transformación. Más bien surge centralmente como el derivado de la dinámica conflictiva por la imposición de sentidos legítimos en una sociedad que pasa a caracterizarse como un orden simbólico atravesado por múltiples antagonismos sociales y estructuralmente fallado.

\footnotetext{
4 En ese sentido, Panizza y Miorelli escriben que "Schmidt nunca explica convincentemente por qué los actores buscarían el cambio o cuáles son las fuentes de sus habilidades discursivas de primer plano" (2013, p. 306-307).

5 La alusión a la propuesta habermasiana de la acción comunicativa y el modelo deliberativo por parte de Schmidt y Pedersen es sintomática, ya que allí la dimensión conflictiva de la política se diluye bajo el ideal regulativo de una comunicación plena. De ese modo, “... en el modelo deliberativo, al menos potencialmente siempre habría un modo racional de resolver los problemas políticos..." (Franzé et al., 2014, p. 79), basado en la práctica compartida de la provisión de razones y la argumentación donde el conflicto aparece de manera accesoria y, en cierto sentido, superficial.
} 


\section{Giro ontológico-discursivo: hegemonía y retórica}

El ID ofrece una perspectiva innovadora que pretende sintetizar los aportes simbólicos dentro de las explicaciones neoinstitucionalistas, así como proponer un modo de analizar a las instituciones al recuperar su dimensión discursiva, entendiendo por esta al proceso interactivo que incluye la coordinación entre actores, la provisión de razones y la comunicación de los resultados y argumentos opuestos que están en la base de la transformación institucional (Schmidt, 2008; 2010). El ID se detiene en el cruce de condicionantes institucionales y discursivos para explicar procesos de cambio institucional. Así, por ejemplo, Schmidt sostiene que sistemas políticos centralizados tienden a remarcar la dimensión comunicativa del discurso, subrayando el vínculo entre dirigentes y el electorado o la ciudadanía, mientras que aquellos sistemas políticos más fragmentados vuelven relevantes los elementos coordinativos del proceso interactivo a la base de una reforma institucional. Además, el ID subraya la influencia del entorno social más amplio en que se inserta el proceso institucional que provee los términos clave con que se comprenden las prácticas e interacciones dentro de un escenario político dado.

Sin embargo, aun al introducir un conjunto de variables simbólicas en el análisis, falta en esta perspectiva un herramental analítico que eche algo de luz sobre la dinámica discursiva por la que ciertas instituciones comienzan a volverse posible objeto de cambio. Para entender una transformación institucional es necesario dar cuenta del modo en que los términos que estructuran el vocabulario político de un momento determinado se van desplazando en relación a algún significante nodal que influye de modo específico sobre ese léxico político más general. Esto supone que los cambios institucionales cristalizan modificaciones políticas producidas de modo histórico y conflictivo. Por caso, las reformas del Estado — fenómeno presente en la mayoría de los casos nacionales y subnacionales de las últimas décadas- pueden tener, y de hecho tuvieron, diversas interpretaciones y diagnósticos. La dirección de los cambios, así como las condiciones que los portavoces de esas "comunidades epistémicas" (Schmidt, 2010, p. 11) pretenden cumplir al realizarlos, dependen 
de los discursos particulares que dan sentido a esas reformas. Ello supone un giro ontológico y epistemológico respecto del modo en que el ID ha tratado a la noción de "discurso".

Precisamente el lenguaje analítico de la Teoría Política del Discurso (TPD), dentro del horizonte ontoepistemológico del postestructuralismo, provee una mirada muy útil sobre los procesos de construcción social de sentido, por lo que se vuelve posible articular ambas miradas para considerar los aspectos institucionales y discursivos que inciden en fenómenos de cambio institucional. El punto de partida ontológico del lenguaje postestructuralista es la constitución discursiva de lo social, lo que ya apunta una diferencia importante respecto del ID: todo elemento de lo social adquiere sentido en relación a otros, es decir al interior de un conjunto relacional de diferencias que no puede delimitarse a priori y de modo definitivo (Laclau y Mouffe, 2004). Como ningún elemento tiene sentido por sí mismo, se vuelve necesario indagar en el modo en que se entablan estas relaciones al interior de un discurso que está constitutivamente dislocado. A partir de aquí, no es posible asumir la realidad social como lo hace el ID, es decir, como una escena objetiva compuesta por individuos o actores colectivos definidos por intereses y valores plenamente formados y capaces de argumentar racional y creativamente sobre las instituciones que habitan.

Frente a estas limitaciones del lenguaje del ID se vuelve posible introducir un giro ontológico que, sin dejar de considerar su potencialidad analítica, parta de considerar la condición fallada del orden social y por ende permita observar los procesos de cambio institucional como espacios conflictivos y eminentemente políticos. Aun cuando las presunciones ontológicas del postestructuralismo suelen ser vistas con sospecha o desdén por los institucionalistas de diverso cuño, aquellas subrayan precisamente lo que estos últimos eluden, esto es, el carácter constitutivo del conflicto social, y por lo tanto, de los intentos políticos por la estabilización del orden social (Schmidt, 2010, p. 15). Lo hacen al sostener una ontología discursiva que muestra que todo orden es simbólico, por un lado, ya que se construye por encadenamientos de significados que no poseen un sentido intrínseco, y 
precario, por el otro, al estar atravesado por una dislocación estructural y una multiplicidad de antagonismos sociales que lo constituyen al mismo tiempo que imposibilitan la plenitud de esa estructura de sentido (Laclau y Mouffe, 2004; Laclau, 2000).

Como dijimos, una ontología discursiva implica que la realidad social se estructura como un discurso, esto es, como un conjunto relacional de diferencias cuya demarcación es indecidible en tanto está estructuralmente dislocado. Este carácter fallado implica que lo social siempre estará en proceso de (re)construcción a lo largo de una dinámica hegemónica de articulación, conflicto y sobredeterminación simbólica. En el supuesto de la objetividad plena de lo social que subyace al ID, la relación entre los elementos en el discurso sería estrictamente literal en un orden dado por alguna instancia transcendente vinculada a una capacidad racional intrínseca de los participantes del proceso institucional. No habría lugar allí para dar cuenta de la dinámica hegemónica y conflictiva de la construcción social de sentido que plantea la TPD, ya que los elementos del sistema aparecerían transparentes e idénticos a sí mismos, pasibles de ser distribuidos plenamente como mónadas dentro de la sociedad. Precisamente, el modo de introducir el discurso por parte del ID no solo desconoce la conflictividad de todo proceso de construcción de sentido, sino que limita lo discursivo a la interacción entre agentes perceptivos que hacen uso del lenguaje como instrumento neutro para proveer razones y ver satisfechos sus intereses donde no hay espacio para el desplazamiento en el valor dado a los términos que configuran el vocabulario político en la base del proceso de cambio institucional.

El uso del discurso por parte de la TPD es radicalmente otro. Al partir de la negatividad constitutiva de cualquier estructura de sentido, se desplaza el carácter pleno del orden social y se lo reemplaza por el orden hegemónico en disputa de sentidos y solo precaria y contingentemente constituido como tal. La plenitud se plantea como necesaria pero en última instancia imposible, por lo que solo se alcanza al precio de ser ilusoria (Laclau, 2000b; 2004; 2014). Su sentido se constituye mediante algo más que la mera disposición relacional de las diferencias, y es en ese registro que opera la lógica hegemónica. De este 
modo, el desplazamiento ontológico de la TPD implica reconocer a las ideas y al discurso en tanto estructurantes parciales de los marcos simbólicos que estructuran los actores, pero a su vez los caracteriza como espacios precarios, fallados, siempre inmersos en un juego de recompletamiento hegemónico que abarca tanto elementos lingüísticos, como extralingüísticos (Laclau y Mouffe, 2004) ${ }^{6}$.

Esa dinámica de articulación hegemónica se produce, según el planteamiento de Laclau a la base de la TPD, mediante la construcción de cadenas de equivalencias entre los elementos particulares de lo social. Frente a la diferencia antagónica, que es producto de la exclusión, se produce un vaciamiento tendencial de alguno de esos significantes que pasa a representar de manera transitoria y nunca plena el lugarde la universalidad - una trascendencia, por ende, siempre contaminada por la particularidad —. El espacio simbólico adquiere así sus límites de manera transitoria y conflictiva mediante un triple y concomitante proceso de articulación entre elementos, vaciamiento del significante nodal y sobredeterminación de este último sobre los primeros, al subvertir la mera relación diferencial entre ellos. Los momentos de la cadena hegemónica retienen algo de su particularidad pero son esencialmente contaminados por la universalidad espuria que se configura hegemónicamente. De este modo, ciertos significantes adquieren un diferencial en su capacidad de interpelación en función de la articulación hegemónica que los constituye parcialmente. Esto hace de la realidad social discursivamente constituida un espacio tensionado y descentrado que está lejos de suponer, como aparece en el ID, una esfera pública neutra donde los individuos persuaden a sus congéneres en favor de uno u otro arreglo institucional. La TPD, a partir de estas nociones de articulación y hegemonía, permite analizar los

\footnotetext{
6 De este modo, la delimitación de manera precisa y asertiva del terreno de la institución y del de la práctica en ella se vuelve imposible. La primera requiere, como su complemento necesario y al mismo tiempo subversivo, de la dimensión performativa que se observa en la práctica. De este modo, la TPD no desconoce el condicionante parcial de las prácticas sedimentadas de los agentes sociales sino que muestra su radical falla. De allí que el foco de su atención esté en la relación indecidible entre el terreno relativamente estructurado de lo social y la práctica política que reactiva a los elementos parcialmente sedimentados.
} 
procesos de transformación institucional vinculándolos con los desplazamientos discursivos de los que forman parte.

Así, el enfoque analítico de la TPD expande la categoría "discurso" al terreno ontológico, por lo que todo elemento social requiere, para ser, de su inscripción en una superficie discursiva constituida hegemónicamente. Laclau utilizó diversas analogías para dar cuenta de los procesos a la base de la emergencia, consolidación y debilitamiento de los procesos hegemónicos (Laclau, 2000b), abrevando en lenguajes teóricos que definen el discurso como un conjunto relacional de signos en el que hay una primacía del significante sobre el significado ${ }^{7}$. Así como el psicoanálisis lacaniano y el proyecto de deconstrucción derrideano, también la retórica contemporánea parte del carácter no fijado, constitutivo y preeminente del significante en el orden del sentido y ha sido una de las fuentes que usó Laclau para dar densidad teórica a la categoría de hegemonía. El teórico político argentino sentó las bases para un ejercicio de articulación teórica entre ambos lenguajes sobre el mismo supuesto de una ontología discursiva, o bien de una retórica generalizada:

Ya están lejos los tiempos en que la transparencia de los actores sociales, de los procesos de representación, incluso de las presuntas lógicas subyacentes al tejido social, podría ser aceptada de manera no problemática. Por el contrario, cada institución política, cada categoría de análisis político, se nos presenta hoy día como el locus de juegos de lenguaje indecidibles. El carácter sobredeterminado de toda diferencia o identidad política abre el espacio de un movimiento tropológico generalizado (...) [que] en mis trabajos (...) ha sido denominado 'hegemonía' (Laclau, 2006, p. 59).

\footnotetext{
La deconstrucción derrideana fue un antecedente central para la obra de Laclau. No obstante, el progresivo acercamiento al psicoanálisis, tanto en su raíz freudiana como en la interpretación de Lacan, supuso la apertura de un campo de estudios muy fecundo para comprender de modo crítico la constitución y los límites de la hegemonía, así como el lugar del sujeto político (Laclau, 2000a; Zizek, 1989; Glynos y Stavrakakis, 2004). Para una mirada sobre el lugar de los tropos retóricos en el psicoanálisis lacaniano, véase Lacan (2014a y 2014b).
} 
Este espacio de la hegemonía como un movimiento tropológico generalizado supone, primero, dar a la retórica un carácter constituyente de la realidad social y mover el análisis de cualquier presupuesto $a$ priori de una estructura de sentido plena, compuesta por partes con significado intrínseco. Segundo, habilita el estudio de las dinámicas de construcción de los entramados simbólicos, de modo tal que es posible rastrear los desplazamientos que dan cuenta del "carácter desnivelado de lo social" (Laclau, 1996, p. 81), los mismos que son condición de posibilidad de los cambios institucionales. En esta dimensión adquieren relevancia las figuras retóricas, especialmente las de la metonimia y la metáfora ${ }^{8}$. Estas constituyen el núcleo de la dinámica significante en tanto regulan los movimientos - troposentre significantes en la construcción de cadenas equivalenciales.

La metonimia y la metáfora son centrales para la TPD ya que, al transgredir el principio de la pura lógica diferencial y representacional que subyace a la lingüística estructural, están a la base del proceso de articulación significante que constituye la hegemonía. Respecto de la primera, Laclau considera que "la hegemonía es siempre metonímica" (Laclau, 2014, p. 110), ya que la metonimia implica la combinación desplazada de elementos por contigüidad. De ese modo, este tropo se asemeja a la dinámica de desplazamiento entre significantes rearticulados por una proximidad parcialmente novedosa que está en el punto de partida del proceso hegemónico. Ante la imposible definición literal de cada uno de los vínculos entre elementos del discurso, la articulación los desplaza en nuevos encadenamientos de significantes, estableciendo nuevas combinaciones posibles de sentido. La metonimia es el tropo que permite comprender la articulación siempre desplazada de significantes más allá de una estructura determinada de lo social, y en deslizamientos de este tipo se encuentran las condiciones de posibilidad de los cambios institucionales. Si toda institución política es el ámbito de "juegos de lenguaje indecidibles" los

\footnotetext{
8 La atención que prestamos a la metáfora y la metonimia no debe hacer olvidar que Laclau profundiza en otras figuras retóricas como la catacresis, que mencionaremos más adelante, o la sinécdoque, de particular importancia en Laclau para comprender la lógica populista (Laclau, 2005).
} 
desplazamientos de estos últimos abren el espacio para nuevos usos de la institución y, por ende, para su transformación.

No obstante, esa contingencia del proceso metonímico nunca es puro flujo de desplazamientos, es decir, la institución tiende a limitar los usos posibles que se hacen de ella porque se encuentra en un espacio simbólico relativamente estructurado con grados variables de sedimentación de lo social. Allí adquiere importancia el tropo de la metáfora que implica, en el terreno de la retórica, la sustitución de significantes por analogía, lo que supone entonces ya no un desplazamiento sino la condensación de sentidos. Laclau sostiene que la metáfora está presente en la lógica hegemónica, en el movimiento de encarnación de la plenitud imposible de la sociedad, en el nombre que simboliza el significante vacío. Dicho vaciamiento implica que el significante sustituye, metafóricamente, el punto de cierre del discurso $^{9}$. De esta manera, la hegemonía requiere de desplazamientos metonímicos y sustituciones metafóricas que imposibilitan analizar la constitución de sentido desde una mirada literal y lineal.

La estructura discursiva solo puede estabilizarse precaria y contingentemente cuando uno de los elementos diferenciales pierde parte de su sentido específico y "contamina" una serie cada vez más extendida de elementos que se articulan en la cadena discursiva. En este proceso, el sentido de estas diferencias se desplaza metonímicamente, de manera contingente, en el marco de más o menos parciales sustituciones metafóricas. En un mismo movimiento, los procesos de articulación son el terreno en que se verifica el vaciamiento del significante mediante el cual los elementos articulados ven modificados parcialmente sus

\footnotetext{
$9 \quad$ En efecto, para el nombre del completamiento no existe un referente en el orden de los significados ya que lo que se sustituye es una ausencia radical de sentido. Allí se evidencia otra figura de la retórica, la constitución de una catacresis. Al respecto, escribe Laclau que “(...) si la representación de algo irrepresentable es la condición misma de la representación como tal, esto significa que la representación (distorsionada) de esta condición supone una sustitución, esto es, solo puede ser tropológica por naturaleza... y como cualquier movimiento figural implica decir algo más de lo que puede ser dicho a través de un término literal, la catacresis es inherente a lo figural como tal, se vuelve la marca registrada de la 'retoricidad' como tal" (Laclau, 2010, pp. 24-25).
} 
particularidades en el marco de la sobredeterminación hegemónica. La articulación hegemónica requiere de ambos movimientos, desplazamientos y sustituciones de sentido, en una dinámica de reenvíos simbólicos. Así, la pura metonimia y la pura metáfora son extremos imposibles de un "continum" donde no existen en tanto tales como plenitud, sino como dimensiones en tensión de toda construcción de sentido (Laclau, 2010, p. 23-24).

Este giro ontológico frente al ID tiene efectos en el modo de pensar las instituciones y su cambio. Como hemos visto, en general las perspectivas neoinstitucionalistas más canónicas plantean la exterioridad entre las reglas a seguir y los agentes que las utilizan (Schmidt, 2008, p. 2), es decir, que entre práctica e institución habría una cesura, por lo que la primera solo podría adecuarse a la segunda, sin incidir en ella. La propia Schmidt plantea que solo al definir las instituciones también como constructos internos a los agentes, con la posibilidad entonces de modificarlas, es posible dar lugar al cambio institucional al traer a colación las habilidades discursivas de primer plano [foreground discoursive abilities], esto es, la capacidad de los agentes de poner en cuestión su propio uso de las instituciones. Pero, como podemos agregar ahora, esa capacidad no se da en un medio simbólico neutral donde los agentes apelan a una racionalidad comunicativa intrínseca, sino que el proceso de cambio institucional se produce en un entramado discursivo descentrado y en lucha por la hegemonía, donde los intentos disputados de sutura hegemónica establecen el marco y las condiciones para comprender cuáles son las condiciones de emergencia, y/o de imposibilidad, de esa voluntad de cambio.

Lo discursivo, entonces, no se agota en el nivel del significado, limitado a ser expresión de referencias de una realidad externa y objetiva, sino que está subvertido por el nivel significante que observamos en la dinámica hegemónica y sus tropos retóricos. El cambio institucional adquiere así un nuevo aspecto, ya que sus condiciones de posibilidad están atravesadas por el desplazamiento metonímico y la condensación metafórica en que se desarrollan las disputas políticas. Estos movimientos, en una dinámica histórica en tensión, radican en la base de la construcción hegemónica de sentido, la que define los 
límites de lo legítimo y, por lo tanto, establece también qué se vuelve necesario transformar o conservar y en qué dirección.

Ello trae implicancias para el análisis de los procesos de cambio institucional ya que la atención pasa a enfocarse en las prácticas que ponen en acto, y al mismo tiempo subvierten, a las instituciones, así como en la lucha hegemónica entre las diferentes posiciones para legitimar estas sedimentaciones o reactivaciones. El carácter fallado de lo simbólico pone de manifiesto la imposibilidad de la mera aplicación técnica y neutral de las instituciones en tanto no puede existir una total superposición en sus sentidos. Por ende, como plantea Laclau,

en las prácticas sociales hay algo más que la puesta en acto de lo simbólico a través de performances institucionalizadas. Allí es donde reside, en nuestro análisis, el momento del antagonismo, el que $(. .$.$) no es... sino el límite que la objetividad encuentra para$ constituirse... (Laclau, 2003, p. 83).

Abrevando en el planteamiento de Laclau, es posible sostener que es en el orden de la práctica discursiva donde se vuelve posible la confrontación antagónica, no necesariamente mediante una disputa abrupta, sino en el propio desplazamiento — ese "algo más que la puesta en acto de lo simbólico"- que habilita cualquier puesta en acto institucional.

De este modo, la práctica discursiva institucional implica un potencial desplazamiento - metonímico- del vínculo entre los elementos relacionados. Como ya hemos visto, dicha combinación contingente emerge en el trasfondo distorsionado por retotalizaciones metafóricas en pugna. Por ello, una práctica institucional no puede reducirse a cierta aplicación mecánica o ingenua de la norma, o agotarse en una discusión racional de sus posibles usos, sino que se constituye en un campo discursivo descentrado y cruzado por dinámicas de lucha hegemónicas.

El vínculo sutil entre las instituciones y las prácticas se vuelve el lugar posible tanto de la sedimentación, como de un desplazamiento o 
"reactivación" (Laclau, 2000a) donde el cambio, más o menos parcial, se vuelve factible. En efecto, la retoricidad generalizada en el marco de la teoría de la hegemonía de Laclau permite entender el cambio institucional en el marco de una modulación subjetiva abierta por la brecha entre práctica e institución. Esta modulación se representa en los desplazamientos significantes al interior de un horizonte relativamente sedimentado de inscripción que es deudora, a su vez, de aquella dislocación constitutiva que se mantiene en todos sus efectos, en tanto posible siempre de ser reactivada y subvertida ${ }^{10}$. En otras palabras, las transformaciones institucionales se producen a partir de desplazamientos y rearticulaciones significativas, en el marco de metaforizaciones y metonimias en conflicto sobre la validez del ordenamiento social más apropiado.

En esta línea, las reformas del Estado de fines del siglo XX y principios del actual, que se verificaron a nivel internacional, nacional y subnacional, constituyen cambios institucionales de alcance variable que se comprenden al interior de dinámicas hegemónicas. Allí los significantes empresa y mercado adquieren una centralidad semántica que sobredetermina a los “juegos de lenguaje indecidibles” cuyo locus es la institución estatal.

En lo que sigue, traeremos a colación un ejemplo de transformación institucional, la reforma del Estado de la provincia de Córdoba en el año 2000, sancionada mediante un conjunto de leyes denominadas genéricamente "Córdoba Nuevo Estado". Subrayaremos el modo en que se vuelven posibles nuevas rearticulaciones significantes de lo institucional — por las que la práctica y la función del Estado se vinculan metafóricamente a la dinámica y los parámetros de una empresa privada - en tanto deviene hegemónico un proyecto neoliberal que coloca a un elemento particular, una específica lógica de

\footnotetext{
10 En este sentido, Laclau escribe que “(...) es un hecho que la puesta en práctica de una regla estricta a través de una actuación [performance] institucionalizada es en última instancia imposible. La aplicación de una regla implica desde el comienzo su propia subversión... toda acción política... tiene un componente paródico, en tanto un cierto significado que estaba fijado dentro del horizonte de un conjunto de prácticas institucionalizadas es desplazado hacia nuevos usos que subvierten su literalidad" (Laclau, 2003, p. 84-85).
} 
mercado, en el lugar de la representación espuria de la universalidad ausente. El cambio institucional y la operación hegemónica del neoliberalismo pueden así analizarse teniendo en cuenta la dimensión retórica constitutiva de la práctica política que configura la relativa estructuralidad en que se ubican los actores políticos para dotar de sentido las propuestas de reforma.

\section{La reforma del Estado cordobés}

La provincia de Córdoba está ubicada en el centro-norte de Argentina, con una relevancia histórica dada por su población, riqueza e incidencia en el escenario político nacional. Desde el retorno democrático, en 1983, se caracterizó por tener un sistema bipartidista en que competían la Unión Cívica Radical (UCR) y el Partido Justicialista (PJ), con predominancia de la primera hasta 1999. En ese año una coalición partidaria liderada por el PJ la desplazó. Bajo el nombre de Unión por Córdoba $(\mathrm{UpC})$, esta coalición reunía al PJ y a partidos menores de tradición neoliberal, como la Unión de Centro Democrático (Ucedé) ${ }^{11}$. Estaba encabezada por el dirigente justicialista José Manuel De la Sota, quien fue su candidato a gobernador y que promovió, en los primeros años de su mandato, una reforma estatal de amplias proporciones. Aludiendo a una modernización generalizada del aparato estatal y a su inclusión en el proceso de globalización mundial, De la Sota presentó en 1999 un conjunto de políticas públicas que pretendían refundar el modo en que el Estado se vinculaba con los actores políticos y sociales.

11 UpC ganó la elección de fines de 1998 con un 49,6 \% de los votos, contra un 40,5\% de la Alianza-UCR. 15,7 \% de los puntos de UpC provinieron de la Ucedé y APEC (Acción para el Cambio), partidos chicos de extracción neoliberal que poseyeron gran relevancia electoral. Germán Kammerath, principal dirigente de Ucedé, con estrechos vínculos con la administración menemista, fue candidato a vicegobernador y luego a intendente de la capital cordobesa. La conformación de UpC reconoce múltiples factores organizativos y estratégicos, atravesados a su vez por la articulación del peronismo cordobés al interior de una hegemonía neoliberal que se consolidó en el país en diversas inscripciones espaciotemporales desde fines de los ochenta (Reynares, 2014). 
Los intentos de reforma del Estado no eran novedosos en la historia política argentina reciente. A nivel nacional, con antecedentes puntuales que se remontan a la última dictadura militar y al gobierno de Alfonsín, a inicios de la década de los noventa la administración de Carlos Menem había desarrollado una amplia reforma que privatizó activos públicos y descentralizó servicios (Oszlak, 2003; Torre, 1998). En Córdoba, los gobiernos radicales de Eduardo Angeloz y Ramón Bautista Mestre, en 1988 y 1995, respectivamente, habían promovido reformas administrativas y fiscales del Estado provincial con diversa suerte. Tanto en la Nación como en la provincia, las reformas se habían presentado como medidas "de shock" puntuales, motivadas por problemas fiscales o financieros críticos y estaban centradas en la reducción del gasto público. En el caso de los gobiernos radicales cordobeses, esos cambios no implicaron grandes modificaciones de los esquemas organizativos de la administración provincial y de la modalidad de relación entre Estado y sociedad. En términos generales, persistió una fuerte presencia activa del primero sobre la segunda (Arriaga et al., 2012; La Serna, 2001; Yuszczyk, 2008), aludiendo en diversas ocasiones a la "solidaridad" como índice de la actividad y de la capacidad del Estado (Closa, 2010, p. 482).

Ahora bien, la reforma del Estado provincial llevada adelante por UpC entre 1999 y 2000, bajo el nombre de "Córdoba Nuevo Estado", tuvo características específicas, ya que se planteó como una transformación integral del Estado sin alusión a crisis en las finanzas que implicasen cierta puntualidad de las reformas (Ase y Burijovich, 2001). Figuras paradigmáticas de este proyecto fueron las Agencias de Gobierno y las leyes del "Nuevo Estado". A través de las primeras se creaban organismos ejecutivos para la coordinación de actores privados y el Estado provincial funcionando como una sociedad de economía mixta, con una asamblea de accionistas que privilegiaría la función de su "gerencia comercial" encargada de evaluar la viabilidad económica de los proyectos a implementar (Reynares, 2014). Las segundas constituían el grueso de la reforma institucional y sus efectos alcanzaban 
a todo el aparato estatal ${ }^{12}$. En general, esta reforma se implementó "mayormente bajo la orientación del paradigma gerencialista promercado" (Lardone, 2003, p. 308), resultado de la influencia del Banco Mundial que fomentaba estos cambios y se había comprometido a proveer financiamiento a la provincia si se los efectuaba (Navarro, 2001; Ase y Burijovich, 2001). El contexto nacional incidía allí de un modo particular. Por un lado, hacia fines de los noventa, el gobierno de C. Menem era criticado por numerosas voces y la reforma estatal nacional era objetada por haber sido ejecutada a través de maniobras corruptas (Pereyra, 2013). Por el otro, el vocabulario reformista persistió en el gobierno de la Alianza, encabezado por Fernando de la Rúa, que sucedió a Menem entre 1999 y 2001. Ello supuso un esfuerzo por parte de $\mathrm{UpC}$ de presentar la reforma provincial como algo distinto, que subrayase la transparencia de la institución estatal y la autonomía respecto de los proyectos del nuevo gobierno nacional, de signo opositor (Segura, 2007). Al mismo tiempo, se presentó desde un principio como una transformación a largo plazo que no dependía estrictamente de la situación financiera local, diferenciándose así de las reformas previas de los gobiernos radicales.

Teniendo en cuenta los contextos tanto nacional como provincial, el cambio institucional requirió de un proceso interactivo en que se proveyeron razones para justificarlo. Si tenemos en cuenta las categorías del ID trabajadas más arriba, se vuelve necesario aludir a las habilidades discursivas de primer plano de los agentes que promovieron la reforma: dirigentes políticos, representantes legislativos, profesionales técnicos y miembros de la administración pública. No obstante, a partir del giro postestructuralista y retórico de nuestro

12 Las leyes del "Nuevo Estado" habilitaban la incorporación mayoritaria de capital privado en la Empresa Provincial de Energía Córdoba (EPEC) y del Banco Provincia de Córdoba, promovía la participación ciudadana a través de los medios tecnológicos, como el correo electrónico, para facilitar el acceso a la información pública, modificaba el régimen de empleo público promocionando la competencia entre empleados para acceder a mejores salarios, otorgaba amplios poderes al gobernador para flexibilizar la gestión, permitía la concesión de los corredores viales provinciales autofinanciables a inversores privados, y creaba la Corporación Inmobiliaria Córdoba para negociar en el mercado de bienes raíces los inmuebles provinciales considerados prescindibles, entre otras muchas medidas (Closa, 2010; Leyes provinciales $\mathrm{N}^{\circ} 8836 / 00$ y No 8837/00). 
análisis, nuestra atención no se agota en las habilidades de esos individuos para producir un argumento crítico de las instituciones. En cambio, hace foco en el campo hegemónico donde ciertos significantes nodales estructuraron los parámetros de legitimidad y validez con que se evaluaron las instituciones políticas y se propusieron las reformas ${ }^{13}$.

En lo que sigue, analizaremos algunas implicancias del discurso hegemónico al interior del cual, desde la enunciación de ciertos referentes de UpC, el Estado provincial pasó a interpretarse como una institución que debía ser cambiada de un modo tal que su dinámica se aproximase a la de cualquier empresa del sector privado. Observaremos esta dinámica de desplazamientos y sustituciones, tanto en las razones vertidas por expertos locales del campo de la economía y la tecnología, involucrados en la dimensión coordinativa de la definición de la reforma, como en la comunicación de esas razones a la ciudadanía por parte de los principales dirigentes de UpC. Nos interesa subrayar que el "marco ideacional" en que se desarrolló este conjunto de políticas públicas, en que se coordinaron y comunicaron los diversos actores implicados en la reforma estatal cordobesa, fue un escenario simbólico cuyo cierre, siempre distorsionado, estaba dado por un recompletamiento metafórico donde el significante "empresa" produjo desplazamientos metonímicos en prácticas discursivas y términos vinculados al ámbito estatal ${ }^{14}$.

Durante la campaña electoral de 1998 los candidatos de UpC remarcaban, en su propuesta de gobierno, la necesidad de un "Estado cristalino y eficaz" que terminase con la presunta corrupción e ineficiencia de los anteriores gobiernos radicales, observable en la combinación

\footnotetext{
13 Enfocar la atención sobre los contextos hegemónicos no implica desconocer el carácter racional de los argumentos esgrimidos por aquellos que proponían las reformas, sino mostrar que esas razones no son solo fruto de una intrínseca capacidad racional, sino que están sobredeterminadas por ciertas dinámicas discursivas que los vuelven más o menos legítimas. 14 Si bien esta distinción entre la dimensión coordinativa y la comunicativa es útil en términos analíticos, hay que destacar que una ontología discursiva mina la posibilidad de diferenciarlos nítidamente, ya que en ambos escenarios existe un atravesamiento de la lucha hegemónica.
} 
de una fuerte presión impositiva y una deficiente calidad de los servicios públicos (Plan de Gobierno, Córdoba Nuevo Siglo, 1998 p. 2). Los impuestos que se cobraban a los ciudadanos - a los que se ubicaba preponderantemente en su calidad de contribuyentes, clientes e inversores del Estado- no se condecía con el producto que el Estado debía ofrecer. El Plan de Gobierno de UpC “Córdoba Nuevo Siglo" se basaba en un diagnóstico de la alicaída situación del Estado provincial que comprendía a este último como si fuese una empresa ${ }^{15}$.

Al mismo tiempo, la necesidad de reforma era presentada por la dirigencia de $\mathrm{UpC}$ sin ligazón a una circunstancia crítica de extrema gravedad. Si bien los anteriores gobiernos radicales habían dejado problemas, la reforma era, sobre todo, una necesidad que surgía de los imperativos de adaptación a la globalización a futuro. Los diversos actores centrales de la coalición gobernante planteaban, a lo largo de la dimensión comunicativa del proceso interactivo, que la reforma era una respuesta local frente al "avance" inevitable de la globalización por oposición a una lógica estatista en los anteriores gobiernos radicales que se vinculaba al "retroceso". En este sentido, la secretaria de Gobierno, Olga Riutort, planteaba que “(...) en el inicio del año 2000, Córdoba despierta de su letargo. Quiere dejar de estar amurallada y bostezando para abrirse al mundo... sabiendo que

15 Es necesario destacar que las razones dadas por los promotores de la reforma no son analizadas en función de una presunta verdad objetiva de los enunciados, como sería en este caso el diagnóstico de corrupción e ineficiencia o, como más adelante veremos, el atraso tecnológico que criticaba De la Sota. Nuestro análisis apunta a subrayar el modo en que la operación hegemónica estructurada en torno a cierta lógica empresarial validó y habilitó el desplazamiento en la manera en que se comprendía la institución estatal, condicionando cómo se evaluaba su accionar y se proponían cambios en su configuración. Al mismo tiempo, no sostenemos aquí que la reforma supuso la imposición de intereses sociales del empresariado local, sino que el cambio institucional fue posible, al menos parcialmente, a partir de la hegemonización de un discurso centrado en la forma-empresa que sobredeterminaba el sentido dado a un número cada vez mayor de relaciones sociales. En este punto, vinculado al modo de concebir al neoliberalismo, nos apoyamos tangencialmente en el trabajo de Foucault, que caracteriza al neoliberalismo como una tecnología de Gobierno centrada en la expansión de una lógica empresarial en todos los ámbitos de la interacción social (Foucault, 2007), es decir, un principio de lectura sostenido en torno a la noción de mercado y empresa privada que se expande en distintas inserciones espaciotemporales (Larner, 2000; Reynares, 2014). 
hoy, la sociedad que no avanza, retrocede..." (en La Voz del Interior, 17/02/2000, p. 13 A).

La inclusión en un proceso ineludible de apertura e inserción al "mundo" se relacionaba, a su vez, con la necesidad de modernización tecnológica frente a la existencia de material electrónico obsoleto y por ende ineficiente. Así, el gobernador De la Sota contaba que al llegar a su despacho se había encontrado con un ordenador "386, con más de diez años de antigüedad. Una computadora que en su época debe haber sido de avanzada, pero que hoy no sirve para controlar la marcha de las reparticiones públicas y sus gastos. Mucho menos para navegar por internet" (en La Voz del Interior, 06/02/2000, p. 15 A).

La insuficiente infraestructura tecnológica suponía la incapacidad del Estado para manejar eficientemente los recursos públicos. Al vincular esta explicación con el diagnóstico sobre los problemas que dejaban los anteriores gobiernos radicales en el Estado provincial, la falta de "adaptación" de este último a los esquemas organizativos típicos de toda empresa lo volvía opaco e ineficiente. El atraso tecnológico y la cerrazón local al movimiento globalizador se relacionaba con una lectura negativa de la situación del Estado provincial. Ello proveía razones "técnicas" para la reforma institucional que adquirían sentido bajo la presunción de que el Estado debía limitarse a la gestión eficiente y controlada de los recursos materiales y que ese objetivo solo podría lograrse mediante la inserción acrítica al orden internacional establecido por la "globalización".

$\mathrm{Al}$ hacer foco en la dimensión comunicativa del proceso interactivo a la base de la reforma institucional, en los argumentos discursivos del gobernador y de su secretaria de Gobierno es posible observar, desde una visión crítica, que el universo simbólico en que estas razones se volvían capaces de justificar los cambios propuestos no era neutral ni obvio, sino el producto de una dinámica hegemónica en la que ciertos significantes adquirían mayor peso y visibilidad que otros, que eran implícitamente criticados. De ese modo, la institución estatal era evaluada a partir de una lectura neoliberal de lo que debía ser el Estado, esto es, funcionar como una empresa que gestiona con el 
menor gasto las mejores prestaciones o utilidades para sus inversores. Este discurso tecnocrático y gerencial se vuelve más evidente en los argumentos esgrimidos por técnicos informáticos que participaron activamente en el desarrollo del proyecto de reforma.

En un libro editado por el Consejo de Profesionales de Ciencias de la Informática de la Provincia de Córdoba (CPCI), llamado Razón de Estado. Bases, premisas y acciones para la transformación del Estado Orientado al Ciudadano ${ }^{16}$, sus autores, luego de mostrar ejemplos de distintos "tableros de comandos" con datos que cada ministerio podría administrar para la evaluación y toma de decisiones, sostenían que:

(...) Los gobernantes deben manejar sus Organizaciones sobre la base de un profundo conocimiento de la cosa pública y con mucho instrumental —entre ellos los sistemas de información ejecutivaque le permiten (...) tomar decisiones acertadas, minimizando los riesgos y las consecuencias... (Razón de Estado 1999, p. 34).

Así, las organizaciones de las que eran responsables los gobernantes no parecían guardar ninguna particularidad, ya que lo importante era poseer información suficiente gracias al "instrumental" tecnológico e informático desarrollado para reducir los costos de la gestión minimizando sus riesgos. En otros fragmentos del libro, otros argumentos en pos de la reforma hacían explícito que el paradigma de organización que el Estado debía utilizar como guía era el de la "forma-empresa" (Foucault, 2007):

(...) La única forma de poder competir en este mundo globalizado es reorganizar las empresas orientándolas hacia los procesos y abandonando el esquema funcional [ya que] los inversores miran

\footnotetext{
16 Su director, Luis A. Crespo, figuraba como miembro de los equipos técnicos de UpC (Documento partidario: Equipos de Técnicos y Profesionales Córdoba Nuevo Siglo", de Unión por Córdoba, 1998), y la participación del CPCI en la reforma fue ratificada mediante una entrevista con un antiguo miembro del CPCI, que todavía en 2013 era empleado público del Estado provincial.
} 
no solo la situación económica, jurídica y social de un país, sino la eficacia y eficiencia del Estado... (Razón de Estado, 1999, p. 18).

Aquí se encuentran otras articulaciones simbólicas que volvían legítimos ciertos cambios institucionales. La inevitabilidad del proceso de la globalización no dejaba margen a la institución para nada más que la competencia, y en pos de este objetivo, el diagnóstico del accionar de un Estado para su eventual transformación debía basarse sobre todo en "la eficacia y la eficiencia del Estado". De este modo, "Estado" y "empresa" se vinculaban de un modo recurrente al punto que el primero perdía toda especificidad para convertirse en una organización empresarial más:

[es necesario] ... que el Estado esté siempre Orientado al Ciudadano, (...) usando las dinámicas de mercado tales como "competencia y alternativa", con el fin de crear incentivos para el éxito (Razón de Estado, 1999, p. 51).

La institución estatal, que debía transformarse como una empresa, asumía así las características básicas de esta última usando "dinámicas de mercado" y definiendo su intervención en la creación de "incentivos para el éxito". Se desplazaba al significante "Estado" de su significado previo —que en gobiernos radicales anteriores había estado vinculado a una presencia activa y específica bajo modelos de "solidaridad social" (Closa, 2010) — para pasar a ser interpretado dentro de los parámetros de una empresa privada en el marco de un proceso de hegemonización neoliberal.

De este modo, la institución estatal era evaluada, diagnosticada - $-\mathrm{y}$ por ende su reforma se proponía - por analogía con los parámetros de una empresa al interior del mercado. Ese desplazamiento de su sentido era posible en tanto la lógica de una empresa privada se presentase como la forma de organización ideal, capaz de actuar de forma técnica y eficiente y de adecuarse a los requerimientos de la globalización que, como hemos visto, aparecía como inevitable y ante la cual era menester adaptarse. La reforma era justificada por parte de agentes que elaboraban críticas sobre el Estado tal como 
venía funcionando previamente en Córdoba, pero no en un universo simbólico neutro, sino en un escenario hegemonizado en el que ciertas realidades, promovidas y difundidas por ellos mismos, aparecían como autoevidentes. En este, la única vía posible para la mejora de la institución estatal implicaba una reforma que permitiese alcanzar los mecanismos para competir en un mundo globalizado, del mismo modo que cualquier empresa privada ${ }^{17}$.

Esta justificación de la reforma estatal a partir de una lectura que reduce esta institución a la gestión, según la lógica empresarial, también está presente en la selección de cuadros políticos intermedios en la gestión de UpC. En palabras de uno de los responsables de la campaña electoral de 1998, defensor de la transformación estatal del año 2000:
(...) Nosotros queríamos un plan, (...) el Plan Córdoba Nuevo Siglo... abierto... y entonces evitar la cuestión de la antigüedad partidaria como condición para ocupar un cargo público depen- diendo de la capacidad de gestión. Nosotros planteábamos que si las políticas estaban bien conducidas a nivel de quien era elegido como el gobernador, su gestión era adaptable por gente que venía de distintas extracciones... a partir de eso, contactamos gente que era absolutamente insospechada que tuviera algún contacto con el peronismo. (...) El plan de gobierno... fue un plan con ideas fuerza, muy atrayente desde el punto de vista del marketing, pero además lo acompañábamos con un listado de profesionales área por área... (entrevista personal con exalto funcionario del Mi- nisterio de Finanzas entre 1999 y 2001, realizada el 30/04/2013).

\footnotetext{
17 Las implicancias de este desplazamiento de sentido del Estado, previamente asociado a una posición activa en la sociedad, bajo el recompletamiento metafórico de la centralidad de la "forma-empresa" son múltiples y aquí solo recuperamos algunos fragmentos donde pueden observarse. También suponen una reinterpretación de la noción del ciudadano como inversor del Estado, al pagar los impuestos, o al evaluar el servicio público recibido como contraprestación. En este punto, la ley provincial No 8835/00, llamada "Carta del Ciudadano" es un buen ejemplo de un desplazamiento del significante "ciudadano" al interior del discurso neoliberal.
} 
El criterio de validez para la gestión no estaba ligado al de la antigüedad partidaria que implicaba cierta experiencia de militancia y dirigencia en el Estado, sino a la capacidad de gestión técnica de la experiencia profesional empresarial. Esta forma de interpretar la pertinencia en el trabajo suponía entonces desconocer la importancia de la organización partidaria — en este caso, la peronista — como espacio de formación política y para la administración pública. Esta "capacidad de gestión" se vinculaba con el "profesionalismo" necesario para implementar la reforma y la lectura del proceso en términos de "marketing". Esto implicaba una equiparación del trabajo dentro del Estado al trabajo en cualquier organización privada que tiene como objetivos prioritarios la maximización de la eficiencia. $\mathrm{Al}$ asumirse al Estado como equivalente a una empresa, en tanto única forma de competir y ser eficiente en un mundo globalizado, la selección de funcionarios se convertía en una cuestión de currículum profesional sin importar la trayectoria partidaria previa ${ }^{18}$.

De ese modo, en los aspectos coordinativo y comunicativo del planteamiento de argumentos para justificar la definición e implementación de la reforma institucional, existía una cierta estructuración hegemónica del universo simbólico que sostenía la centralidad de la "forma-empresa". Esta negaba los conflictos constitutivos tanto en la sociedad como en el seno mismo del Estado y sobredeterminaba el abanico de opciones políticas sobre el que argumentaban los miembros involucrados en la institución estatal. Así, el diagnóstico de la situación provincial durante la campaña electoral, la introducción de tecnología como núcleo del mensaje público y la composición de los equipos de trabajo y asesoría en $\mathrm{UpC}$, se realizaban bajo los parámetros que resultaban de una equiparación neoliberal del Estado a los valores de una empresa privada cualquiera, donde la política se

\footnotetext{
18 En este caso podemos observar que también asume gran importancia, en la delimitación ideológica de quienes participan en el diseño e implementación de una política pública, la definición de un "régimen de conocimiento", es decir, el sistema compuesto por las maquinarias institucionales y organizacionales que producen datos, investigación, recomendaciones de política pública, y otras ideas que influyen en el debate público (Campbell y Pedersen, 2014).
} 
confinaba a la mera gestión técnica adaptada a la marcha inevitable de los mercados.

\section{Algunas notas para concluir}

Las reformas del Estado son procesos de cambio institucional que han promovido numerosos estudios desde el lenguaje del neoinstitucionalismo en las últimas décadas. Como hemos visto, el ID emerge como un intento por incluir, en el análisis de los cambios de las instituciones, el modo en que los agentes comprenden a la práctica institucional y ponen en palabras su interpretación sobre ellas. Así, a partir de las razones que dan los miembros de esas instituciones, se analizan los motivos que posibilitan aquellos cambios, por lo que cualquier explicación de estos últimos necesita tomar en cuenta la dimensión discursiva de la realidad social. No obstante, en el ID hay una caracterización del discurso que lo reduce a una expresión racional en un marco simbólico pleno y neutral, tal como lo propone el planteamiento habermasiano, reduciendo el lenguaje a una expresión representacional de la realidad externa, negando la dimensión performativa y en disputa hegemónica del orden significante.

A partir de algunas nociones de la TPD — que considera que la realidad social está constituida y sobredeterminada discursivamente en tanto conjunto relacional de diferencias que se estructura parcial, conflictiva y contingentemente a través de una dinámica de lucha hegemónica - presentamos una crítica a las limitaciones de estas perspectivas racionalistas. Ello supone destacar que los marcos simbólicos que construyen los agentes que promueven los cambios institucionales no son neutros ni objetivos, sino que están constitutivamente descentrados y relativamente estructurados por un juego conflictivo y contingente de deslizamientos y sustituciones significantes.

En el caso de la reforma estatal de la Provincia de Córdoba, observamos que los dirigentes políticos y técnicos involucrados en dicho proceso interactivo de cambio, tanto en su dimensión comunicativa como coordinativa, justificaban y legitimaban la reforma del Estado 
a partir de un uso metafórico de la forma empresa, por la que el Estado pasaba a ser evaluado, diagnosticado y, a partir de allí, transformado como si fuese una empresa privada actuando en el mercado. La interpretación de la administración estatal según parámetros de la gestión empresarial — bajo la rúbrica de la eficiencia, competitividad, transparencia y adaptación al presunto avance tecnológico y la supuestamente inevitable globalización - fue posible entonces bajo una retotalización metafórica que suponía la expansión de una lógica de libre mercado y de empresa en todos los ámbitos de la interacción social. Los desplazamientos significantes que rastreamos en el último apartado, de clara raigambre tecnocrática y neoliberal, consolidaron dicha hegemonización, al mismo tiempo que esta última los hizo posibles.

Además de destacar el peso explicativo de las estrategias desplegadas por los promotores de la reforma, y más allá de las condiciones institucionales del sistema político cordobés, el giro ontoepistémico que caracteriza a la TPD permite rastrear cuáles fueron las condiciones discursivas de posibilidad para que se promueva una transformación del aparato estatal en tanto emulación de una dinámica empresarial. A lo largo del artículo pretendimos atender a los desplazamientos metonímicos y las retotalizaciones metafóricas que están a la base de la dinámica hegemónica, ya que ello permite subrayar el carácter conflictivo y contingente de la política y, por ende, de los cambios institucionales que jalonaron la historia política argentina reciente.

\section{Referencias}

Arriaga, A. et al. (2012). Un Estado en transición: Córdoba ante el embate neoliberal. En Gordillo, M. et al. La protesta frente a las reformas neoliberales en la Córdoba de fin de siglo, pp. 25-63. Córdoba: Ferreyra Editor.

Ase, I. \& Burijovich, J. (2001). La reinvención del estado cordobés: Una "reingeniería" de la ciudadanía. Revista Administración Pública \& Sociedad, (14), 169-193.

Campbell, J. \& Pedersen O. (2001). The Rise of Neoliberalism and Institutional Analysis. Princeton: Princeton University Press. 
Campbell J. \& Pedersen, O. (2014). Knowledge Regimes and the National Origins of Policy Ideas. En The National Origins of Policy Ideas: Knowledge Regimes in the United States, France, Germany and Denmark. Princeton: Princeton University Press.

Clemens, E. \& Cook, J. (1999). Politics and Institutionalism: Explaining Durability and Change. En Annual Review of Sociology, 25, pp. 441-466. Doi: 10.1146/annurev.soc.25.1.441

Closa, G. (2010). La recuperación de la democracia y los gobiernos radicales. Angeloz y Mestre (1983-1999). En Tcach, C. (coord.), Córdoba bicentenaria. Claves de su historia contemporánea. Córdoba: Centro de Estudios Avanzados, pp. 463-492.

Foucault, M. (2007). Nacimiento de la biopolítica. Buenos Aires: Fondo de Cultura Económica.

Franzé, J., López de Lizaga, J. L., Benedicto, R., Herrero, M. \& Lesgart, C. (2014). Agonismo y deliberación: diferencias conceptuales entre dos perspectivas sobre política y conflicto. Revista Andamios, 11 (24). México: Universidad Autónoma de la Ciudad de México.

Haas, P. M. (1992). Introduction: Epistemic Communities and International Policy Coordination. En International Organization, 46 (1), 1-35. Doi: 10.1017 / S0020818300001442

Habermas, J. (1998). Facticidad y validez. Sobre el derecho y el Estado democrático de derecho en términos de teoría del discurso. Madrid: Trotta.

Hall, P. (1989). The Political Power of Economic Ideas: Keynesianism across Nations. Princeton: Princeton University Press.

Hall, P. \& Taylor, R. (1996). Political Science and the Three New Institutionalisms, Revista Political Studies, 44 (5), 936-957. Doi: 10.1111/j.14679248.1996.tb00343.x

Glynos, J. \& Stavrakakis, Y. (2004). Encuentros del tipo real. Indagando los límites de la adopción de Lacan por parte de Laclau. En Critchley, S. y Marchart, O. (Comps.) Laclau: aproximaciones críticas a su obra. Buenos Aires: Fondo de Cultura Económica.

Lacan, J. (2014a). Función y campo de la palabra y del lenguaje en el psicoanálisis. En Lacan, J. Escritos Tomo I. Buenos Aires: Siglo XXI editores. Lacan, J. (2014b). La instancia de la letra en el inconsciente o la razón desde Freud. En Lacan, J. Escritos Tomo I. Buenos Aires: Siglo XXI editores. Laclau. E. (1996). Emancipación y diferencia. Buenos Aires: Ariel. 
Laclau, E. (2000a [1993]). Nuevas reflexiones sobre la revolución de nuestro tiempo. Buenos Aires: Editorial Nueva Visión.

Laclau, E. (2000b). Discurso (trad. Daniel Saur). En Topos y tropos, 1, (1), 1-7. Laclau, E. (2003). Identidad y hegemonía: el rol de la universalidad en la constitución de lógicas políticas. En Butler, J., Laclau, E. y Zizek, S. Contingencia, hegemonía y universalidad. Diálogos contemporáneos desde la izquierda. Buenos Aires: Fondo de Cultura Económica.

Laclau, E. (2005). La razón populista. Buenos Aires: Fondo de Cultura Económica.

Laclau, E. (2006). Misticismo, retórica y política. Buenos Aires: Fondo de Cultura Económica.

Laclau, E. (2010). Articulación y los límites de la metáfora (trad. Daniel Groisman). En Studia Politicae, (20), 18-38.

Laclau, E. (2014). Los fundamentos retóricos de la sociedad. Buenos Aires: Fondo de Cultura Económica.

Laclau, E. \& Mouffe, C. (2004 [1987]). Hegemonía y estrategia socialista. Hacia una radicalización de la democracia. Buenos Aires: Fondo de Cultura Económica.

La Serna, C. (2001). Reforma y democracia: el caso del Estado de la Provincia de Córdoba en el período 1995/1997. En Administración Pública y Sociedad, (14), 121-136.

Lardone, M. (2003). La reforma de los estados provinciales en la Argentina: hacia la construcción de un esquema analítico. En $S A A P$ 1, (2), 273-316.

Larner, W. (2000). Neo-Liberalism: Policy, Ideology, Governmentality. Revista Studies in Political Economy, (63), 5-25.

March, J. \& Olsen, J. (1989). Rediscovering Institutions. The Organizational Basis of Politics. New York: The Free Press.

Navarro, M. (2001). Las reformas de segunda generación en Córdoba (Argentina): intenciones, legados y derivas políticas. En Actas del VI Congreso Internacional del CLAD sobre la Reforma del Estado y de la Administración Pública. Buenos Aires.

Oszlak, O. (2003). El mito del Estado mínimo: una década de reforma estatal en Argentina. En Desarrollo Económico, 42 (168), 1-28. Doi: $10.2307 / 3455903$ 
Panizza, F. \& Miorelli, R. (2013). Taking Discourse Seriously: Discursive Institutionalism and Post-Structuralist Discourse Theory. En Political Studies, 61 (2), 301-318. Doi: 10.1111/j.1467-9248.2012.00967.x

Pedersen, O. (2008). Nine or So... Questions to Institutional Theory. A

Revised Note on Understanding Institutional Change. Working paper

No. 62, Copenhagen: International Center for Business and Politics,

Copenhagen Business School.

Pereyra, S. (2013). Politica y transparencia. Buenos Aires: Siglo XXI editores. Reynares, J. M. (2014). El neoliberalismo cordobés. La trayectoria identitaria del peronismo provincial, 1987-2003. Tesis doctoral sin publicar. Centro de Estudios Avanzados, Universidad Nacional de Córdoba.

Rothstein, B. (2001). Las instituciones políticas: una visión general. En Goodin, R. y Klingemann, H.-D. (Eds.) Nuevo manual de ciencia política. Madrid: Itsmo.

Sabatier, P. \& H.C. Jenkins-Smith (Eds.) (1993). Policy Change and Learning: An Advocacy Coalition Approach. Boulder, CO: Westview.

Schmidt, V. (2008). Bringing Ideas and Discourse Back into the Explanation of Change in Varieties of Capitalism and Welfare State. Working paper in The Centre for Global Political Economy, University of Sussex.

Schmidt, V. (2010). Taking Ideas and Discourse Seriously: Explaining Change through Discursive Institutionalism as the Fourth "New Institutionalism". En European Political Science Review, 2 (1), 1-25. Doi: 10.1017/S175577390999021X

Segura, M. S. (2007). Unión por Córdoba: la producción de una diferencia.

En Costa R. y Mozejko, T. Lugares del decir 2. Rosario: Homo Sapiens. Torre, J. C. (1998). Elproceso politico de las reformas económicas en América Latina. Buenos Aires: Editorial Paidós.

Yuszczyk, E. (2008). Reforma del Estado y ciudadanía en Córdoba. Un análisis de los discursos politicos de Angeloz, Mestre y De la Sota. Tesis de Maestría en Administración Pública. IIFAP, Universidad Nacional de Córdoba.

\section{Fuentes}

- Diario La Voz del Interior. Corpus seleccionado y recopilado entre 1999 y 2000 .

- Programa de Gobierno "Córdoba Nuevo Siglo" (1998). Documento partidario de Unión por Córdoba. 
- Equipos de Técnicos y Profesionales "Córdoba Nuevo Siglo" (1998). Documento partidario de Unión por Córdoba.

- Crespo, L., Benard, O. \& Bertona, F. (1999). Razón de Estado. Bases, premisas y acciones para la transformación del Estado orientado al ciudadano. Córdoba: CPCI.

- Entrevista personal del autor con empleado administrativo de la Provincia de Córdoba, antiguo miembro del Consejo Profesional de Ciencias Informáticas de la Provincia de Córdoba, bajo solicitud de anonimato, realizada en noviembre de 2013.

- Entrevista personal del autor con exalto funcionario del Ministerio de Finanzas de la Provincia de Córdoba entre 1999 y 2001, realizada el 30 de abril de 2013.

- Leyes Provinciales 8835/00; 8836/00; 8837/00. 